\title{
A População de GoIÁs na TRansição da Mineração Para a PeCuÁRIA (1804)
}

The Population of GoIÁs In THE TRANSITION FROM MinING TO LIVESTOCK (1804)

Hamilton Afonso de Oliveira* hamiltonafonso@bol.com.br

RESUMO: O presente ensaio pretende fazer uma análise do perfil da população de Goiás em princípios do século XIX, período que pode ser caracterizado como de transição da mineração para a pecuária. O objetivo é traçar aspectos do perfil demográfico a partir dos dados do levantamento estatístico publicado em 1804, pelo então capitão Geral da Capitania de Goiás Francisco de Assis Mascarenhas e da obra Memória sobre o descobrimento, população e cousas mais notáveis da Capitania de Goyaz do Cônego Luís Antônio da Silva e Souza. A partir das informações descritas por Silva e Souza sobre as principais características dos julgados então existentes em Goiás, os dados foram analisados com base na atividade econômica dominante alicerçada nas seguintes atividades: mineradora, agropastoril e mineradora/agropastoril. A análise comprovou que além de aspectos peculiares da distribuição da população de cada região revelam-se, também, perspectivas que caracterizam uma sociedade em transição de mineração para a pecuária.

PALAVRAS-ChAVE: Goiás, População, Sociedade.

ABSTRACT: This paper aims at making a profile analysis of the population of Goiás in the early $19^{\text {th }}$ century, a period that can be characterized as transitional from mining to livestock. The goal is to draw on the aspects of the demographic profile from the statistical survey data published in 1804 by the then General Captain of the Captaincy of Goiás Francisco Mascarenhas and from the work Memória sobre o descobrimento, população e cousas mais notáveis da Capitania de Goyaz by the Canon Luis Antonio da Silva e Souza. From the information described by Silva e Souza on the main characteristics of the then existing Julgados in Goiás, the data were analyzed based on the dominant economic activities which were: mining, agropastoral and mining/agropastoral. The analyses proved that, besides specific aspects of population distribution of each region, aspects that characterize a society in transition from mining to livestock were also revealed.

KEYWORDS: Goiás, Population, Society.

A história da ocupação de Goiás insere-se no mesmo contexto histórico de ocupação do Nordeste Paulista e do Triângulo Mineiro. Com a descoberta de ouro em Minas Gerais, Mato Grosso e Goiás na primeira metade do século XVIII intensificaram as correntes migratórias em direção ao oeste, até então, pouco conhecido e inexplorado. Durante a primeira metade do século XVIII, capitania de São Paulo estendia suas fronteiras abrangendo territórios que hoje correspondem aos Estados de Minas Gerais, Goiás, Tocantins, Mato Grosso, Mato Grosso do Sul, Paraná, Santa Catarina e Rio Grande do Sul. Para Brioschi:

[...] a descoberta de ouro em Minas Gerais, Goiás e Mato Grosso pelos paulistas, não foi uma obra da casualidade. Durante dois séculos eles penetravam o sertão adentro caçando índios e sonhando com a descoberta

\footnotetext{
* Doutor em História pela Universidade Estadual Paulista/UNESP-Franca, Mestre em História das Sociedades Agrárias pela Universidade Federal de Goiás, Professor de História do Brasil no Curso de História e do Programa de Pós-Graduação Ambiente e Sociedade da Universidade Estadual de Goiás/Câmpus-Morrinhos-GO.
} 
de ouro, prata ou pedras preciosas, em uma época que os paulistas tinham apenas duas opções: a entrada pelo sertão ou a lavoura de subsistência. Os primeiros caminhos em direção ao ouro saiam da Vila de Pirapitinga de São Paulo, sendo terrestres para Minas Gerais e Goiás e fluvial para Cuiabá (BRIOSCHI, 1991, p.2).

As notícias da descoberta de jazidas auríferas acabaram motivando a primeira onda de migrantes para Goiás que tinham a intenção, em princípio, pela facilidade de riqueza obtida pela mineração do ouro nas rochas e, sobretudo, nos leitos dos córregos e rios. Os primeiros entrantes se estabeleciam em determinada localidade aurífera e, em seguida, reivindicava o direito de posse a títulos de sesmarias. Nestas localidades, além das minas, constituíram-se os primeiros sítios e fazendas que tinham a finalidade de abastecer de gêneros alimentícios as regiões mineradoras. Foi, também, nas proximidades das minas que emergiram os primeiros povoados e arraiais, que logo, se tornaram vilas e cidades. Esta primeira leva de migrantes, provavelmente, era composta em sua maioria de paulistas ávidos por ouro e pelas demais possibilidades de riquezas que o valioso metal poderia oferecer:

[...] esses pioneiros do processo de ocupação desenvolviam suas atividades agropastoris à moda dos bandeirantes: plantação de pequenas roças que em princípio deram lugar aos primeiros pousos que em seus primórdios deveriam ser simples ranchos, à margem das estradas e minas (OLIVEIRA, 2006, p. 21).

A partir do último quartel do século XVIII com a crise na produção aurífera, conforme Brioschi (1991), de forma gradativa, ao longo do caminho para Goiás começou a ocorrer um crescimento significativo de mineiros, que oriundos do sul de Minas que foram se estabelecendo de forma paulatina e ocupando as terras inexploradas do oeste paulista e sul de Goiás (incluindo, o Triângulo Mineiro que, até 1816, era território goiano). Era o início de uma segunda corrente migratória agora, composta principalmente de mineiros originários principalmente do sul de Minas Gerais. Segundo dados de Chiachiri, a participação dos migrantes mineiros na população total da população do Sertão de Goiás cresceu de 24\% em 1804 para 75\% em 1824 (RIOSCHI apud OLIVEIRA, 2008, p. 174).

Com o fim do sistema sesmarial, em $1822^{1}$, a posse tornou-se "a única forma de aquisição de terras baseada no costume, na tradição, imposta muitas vezes pelos

\footnotetext{
${ }^{1}$ Resolução de 17 de junho de 1822: “Houve SMI por bem resolver a consulta que subiu à sua augusta presença com data de 8 de julho do ano próximo passado pela maneira seguinte: Fique o suplicante na posse das terras
} 
condicionamentos socioeconômicos. As posses tornaram-se finalmente legítima e mais tarde foram demarcadas e legalizadas por meio de processos judiciais" (ALENCAR LUZ, 1982, p.2930). Com o fim do sistema sesmarial, a distribuição de terras no Brasil ficou em aberto e seu apossamento ficou desgovernado, o que, aliando à crise da produção aurífera nas regiões mineiras, acabaram motivando a imigração em massa em direção ao oeste, seguindo o caminho paulista para Goiás e Mato Grosso. Segundo Brioschi:

[...] abrindo picadas os entrantes mineiros vieram procurar no sertão bons pastos e novas expectativas de vida, arranchando-se em algum sítio que Ihes aparecia aprazível e delimitavam a olho a sua área. No trabalho de demarcação erguiam cruzes e cravavam ferros em troncos de árvores. Tiravam rego d'água de algum ribeirão e faziam suas roças, erguiam casas, construíam currais, monjolos e demais benfeitorias necessárias à atividade agropastoris. Desta forma, a posse estava assegurada e, os posseiros institucionalizaram-se como senhores (BRIOSCHI, 1991, p.44).

Mapa 1- Triângulo Mineiro, Sul e Sudoeste de Goiás:

Estradas e Arraiás Fundados no Século XIX

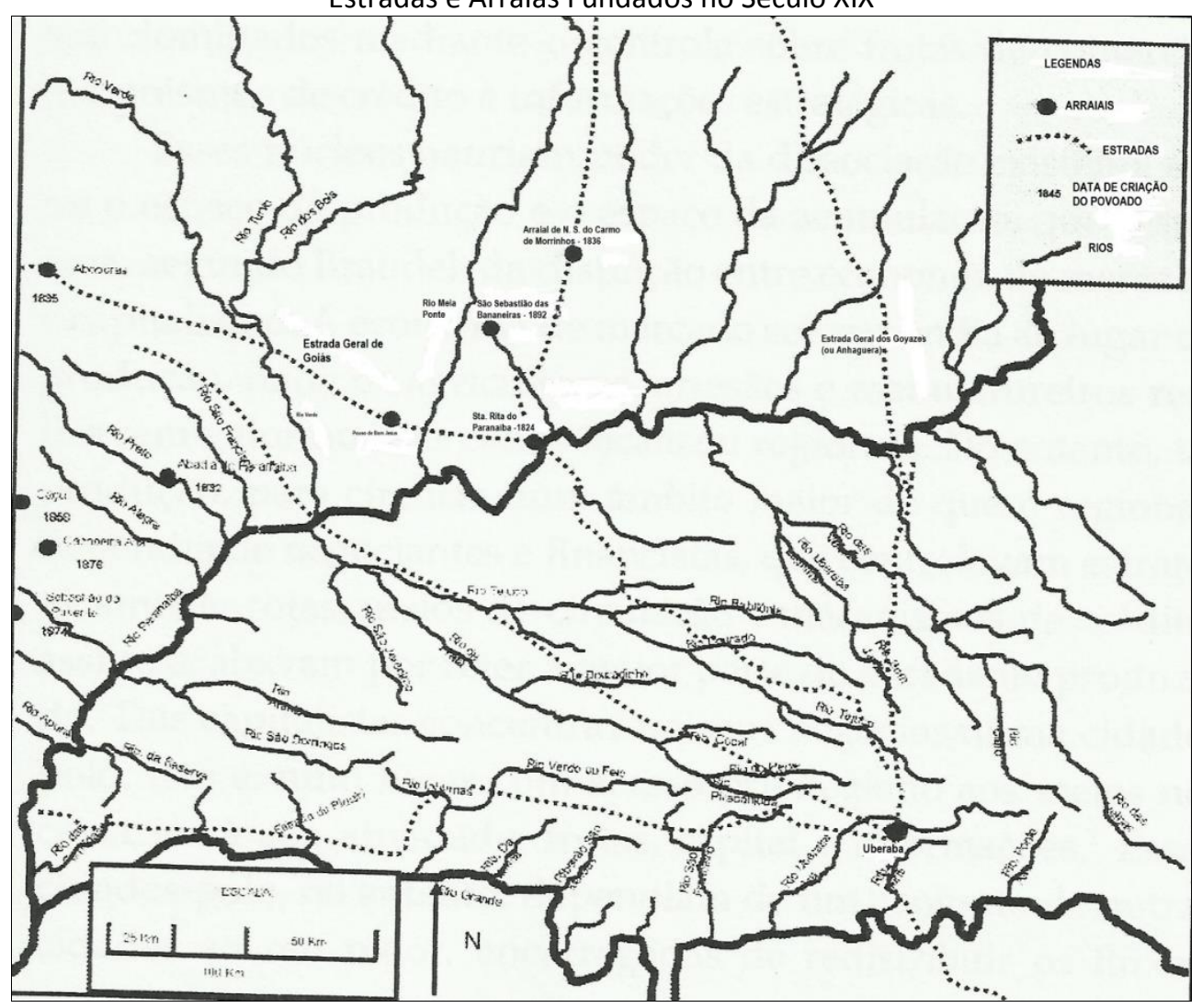

Fonte: LOURENÇO $(2010$, p.73)

Portanto, a ocupação mais efetiva das terras de Goiás se deu em um contexto marcado pela ausência de uma legislação fundiária, redução da produção aurífera em Minas 
Gerais e Goiás. Minas Gerais na primeira metade do século XIX teve que passar por uma reestruturação em suas atividades econômicas e começou a produzir gêneros de primeira necessidade, em larga escala, para o abastecimento interno ${ }^{2}$. Todos estes fatores podem ter sido preponderantes para motivar os deslocamentos migratórios para o norte, nordeste e, principalmente para o sul goiano provocando a ocupação definitiva de todo o seu território no decorrer do século XIX.

Quadro 1 - Origem dos Noivos e Noivas

Vila Bela de Nossa Senhora do Carmo de Morrinhos/GO(1835-1854)

\begin{tabular}{|c|c|c|}
\hline Localidade & Província & Numero de ocorrências \\
\hline N.S. do Carmo de Morrinhos & Goiás & 40 \\
\hline São Francisco das Chagas & Minas Gerais & 10 \\
\hline Freguesia de Dores do Araxá & Minas Gerais & 09 \\
\hline Sta. Anna da Barra do Espírito Santo (Araxá) & Minas Gerais & 08 \\
\hline Freguesia de Santa Cruz & Goiás & 07 \\
\hline Vila de Pihauí & Minas Gerais & 05 \\
\hline São Domingos do Araxá & Minas Gerais & 04 \\
\hline Vila de Patrocínio & Minas Gerais & 03 \\
\hline Dores de Indaiá & Minas Gerais & 03 \\
\hline Arraial do Carmo & Minas Gerais & 02 \\
\hline Vila de Catalão & Goiás & 02 \\
\hline Freguesia de Campo Belo & Minas Gerais & 02 \\
\hline Dores do São Francisco & Minas Gerais & 02 \\
\hline Freguesia de Pitangui & Minas Gerais & 02 \\
\hline Nossa Senhora do Livramento & Minas Gerais & 02 \\
\hline São João Del rei & Minas Gerais & 01 \\
\hline São Pedro Alcântara & Minas Gerais & 01 \\
\hline Arraial de Três Portos & Pernambuco & 01 \\
\hline Santo Antônio do Monte (Bispado de Mariana) & Minas Gerais & 01 \\
\hline Dores do Rio Grande & Minas Gerais & 01 \\
\hline Jundiaí & São Paulo & 01 \\
\hline Vila de Lajes (Bispado de Mariana) & Minas Gerais & 01 \\
\hline Freguesia de Monte Alegre & Minas Gerais & 01 \\
\hline Freguesia de Nossa Senhora do Sacramento & Minas Gerais & 01 \\
\hline Meia Ponte & Goiás & 01 \\
\hline Vila de Uberaba & Minas Gerais & 01 \\
\hline Arraial do Espírito Santo & Pernambuco & 01 \\
\hline Arraial de Santa Anna & Minas Gerais & 01 \\
\hline Sta. Anna do Rio das Velhas & Minas Gerais & 01 \\
\hline Arraial de Rio das Pedras & Minas Gerais & 01 \\
\hline $\begin{array}{l}\text { Total de ocorrências com informação da } \\
\text { procedência dos noivos e noivas }\end{array}$ & & 116 \\
\hline
\end{tabular}

Fonte: Registro de Casamentos da Paróquia de Nossa Senhora do Carmo de Morrinhos (1835-1854)

Conforme informações apresentadas nos registros de casamentos da Paróquia de Nossa Senhora do Carmo de Morrinhos, as localidades mencionadas nestes documentos

\footnotetext{
${ }^{2}$ As Regiões Sul e Sudoeste de Minas Gerais cresciam mais depressa que as outras e, a agropecuária, dominava as economias locais na vasta comarca do rio das Mortes ao sul (ESCHWEGE apud BERGAD, 2004. p.78-79).
} 
mostram que dos casamentos realizados entre os anos de 1835 a 1854, 54,3\% (63) dos noivos e noivas eram originários da Província de Minas Gerais e, 43\% (50) de Goiás, sendo que a maioria destes, (40) já era nascida em Vila Bela de Nossa Senhora do Carmo de Morrinhos. Conforme Mapa 1, a procedência destes noivas e noivas de origem mineira, eram originários das Comarcas Paracatú, Rio das Velhas e Rio das Mortes.

\section{Mapa 2 - Minas Gerais em 1833}

Aproximação das Fronteiras das Comarcas e Localização dos Municípios

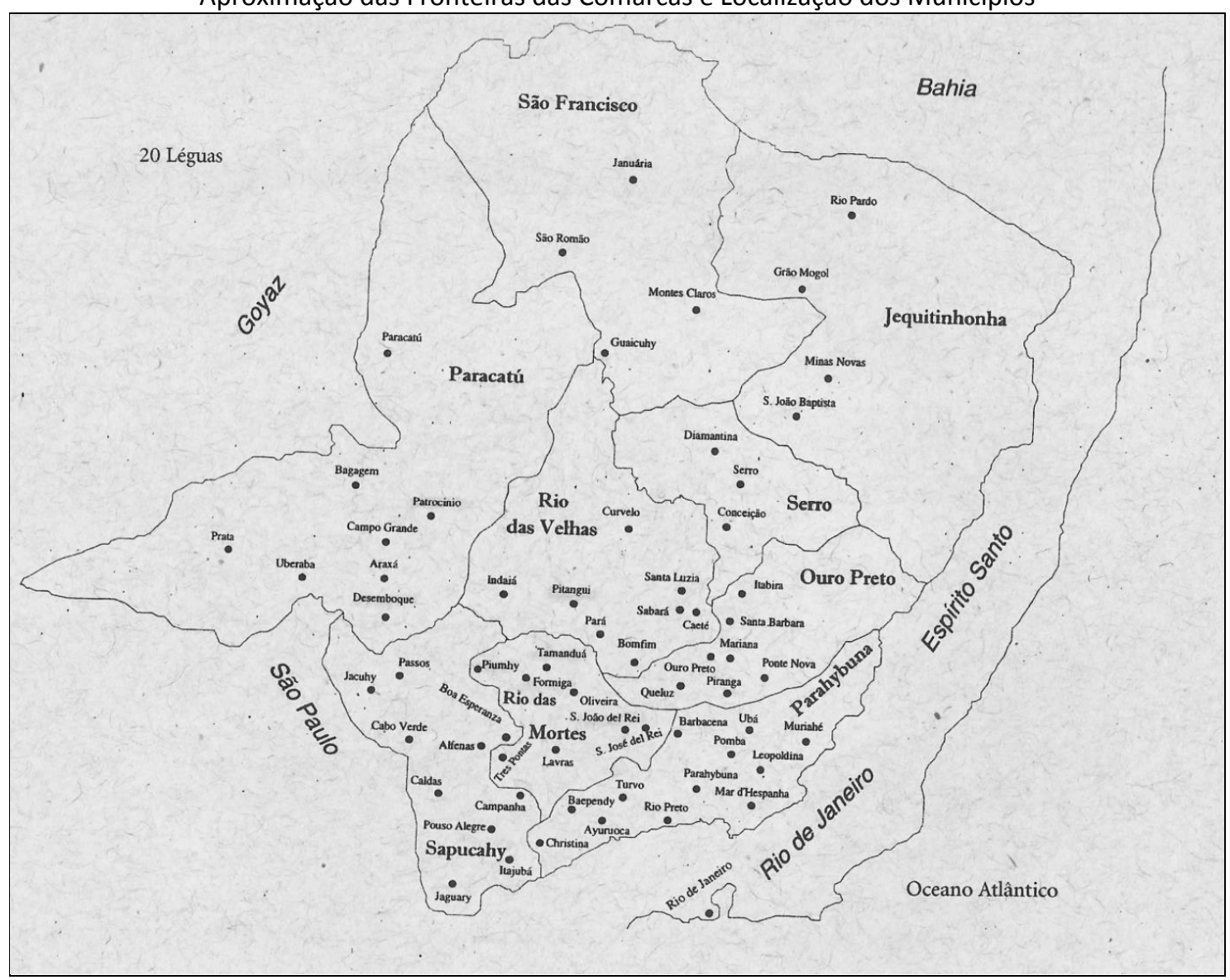

Fonte: BERGAD (2004, p. 39)

Se comparadas com os estudos realizados por Laird W. Bergad (2006), as localidades mencionadas nos registros de casamento, em sua grande maioria, estavam passando por expressivas transformações econômicas nas primeiras décadas do século XIX, especialmente, com o estabelecimento da Coroa Portuguesa no Brasil em 1808:

[...] com a abertura dos portos brasileiros aos navios de todas as nações que não estivessem em guerra com Portugal ou a Inglaterra, foram eliminadas as restrições comerciais e retiradas quase todas as proibições de fabricação impostas no período colonial, assinalando o início de uma nova era de relativa liberdade econômica (BERGAD, 2006, p. 77). 
A partir de princípios do século XIX, conforme pesquisas de Laird Bergad (2006), Minas Gerais passou a desenvolver uma economia mais diversificada ligada à criação e manejo de gado de corte, agricultura, manufatura têxtil, produção de agromanufaturados voltada para o abastecimento interno, especialmente, destinada aos mercados do Rio de Janeiro, então sede da Corte Imperial, que teve sua população dobrada entre os anos de 1808 e 1822, "passando de 50.000 para 100.000 habitantes, o que aumentou as possibilidades de mercado para agricultores e pecuaristas de Minas" (BERGAD, 2006, p. 78). Nas primeiras décadas do século XIX, Minas Gerais, a partir do momento que a produção aurífera entrou em franco declínio passou a dedicar-se com mais afinco a atividades ligadas à agricultura, agromanufaturados e pecuária conforme nota-se no Quadro a seguir:

Quadro 2 - Volume das Exportações de Minas Gerais

\begin{tabular}{|c|c|c|c|c|c|c|}
\hline Produtos & $1818-19$ & $\%$ & 1828 & $\%$ & $1838-39$ & $\%$ \\
\hline Café & $29: 217 \$ 000$ & $2,7 \%$ & $81: 269 \$ 000$ & $4,2 \%$ & $365: 210 \$ 000$ & $20,5 \%$ \\
\hline Tabaco & $70: 377 \$ 000$ & $6,5 \%$ & 264:160\$000 & $13,9 \%$ & 266:546\$000 & $14,9 \%$ \\
\hline Sub-Total & 99:594\$000 & $9,2 \%$ & 345:429\$000 & $18,1 \%$ & 631:756\$000 & $35,4 \%$ \\
\hline Tecido de algodão & $186: 382 \$ 00$ & $17,2 \%$ & 284:022\$000 & $15 \%$ & 163:734\$00 & $9,2 \%$ \\
\hline Queijos & 105:961\$000 & $9,8 \%$ & 68:756\$000 & $3,6 \%$ & $79: 801 \$ 000$ & $4,5 \%$ \\
\hline Toucinho & 290:957\$000 & $26,9 \%$ & 232:177\$000 & $12,2 \%$ & 289:770\$000 & $16,2 \%$ \\
\hline Sub-Total & 583:300\$000 & $53,9 \%$ & 584:955\$000 & $30,8 \%$ & 533:305\$000 & $29,9 \%$ \\
\hline Gado & $248: 424 \$ 000$ & $23 \%$ & 725:040\$000 & $38,2 \%$ & 495:265\$000 & $27,8 \%$ \\
\hline Porcos & 120:507\$000 & $11,1 \%$ & $145: 857 \$ 000$ & $7,7 \%$ & $95: 288 \$ 000$ & $5,3 \%$ \\
\hline Cavalos & $30: 570 \$ 000$ & $2,8 \%$ & $98: 310 \$ 000$ & $5,2 \%$ & $28: 888 \$ 000$ & $1,6 \%$ \\
\hline Sub-Total & 399:497\$000 & $36,9 \%$ & $964: 207 \$ 000$ & 51,1 & 619:441\$000 & $34,7 \%$ \\
\hline Total & 1.082:395\$000 & $100 \%$ & 1.899:599\$000 & $100 \%$ & 1.784:502\$000 & $100 \%$ \\
\hline
\end{tabular}

Fonte: Planilha organizada a partir de dados de BERGAD (2004, p. 93)

De acordo com os dados contidos no Quadro 2, pressupõe-se, que já na primeira metade do século XIX, a economia mineira passou por transformações expressivas que levou adiante a demanda do crescente mercado interno, criado a partir de 1808 . Houve um aumento da capacidade produtiva da província que, de acordo, com o volume das exportações a agricultura, a agromanufatura e a pecuária tinham uma participação equivalente entre os anos de 1818 a 1839, com destaque para o crescimento da produção agrícola, especialmente, a lavoura cafeeira e do tabaco; a exportação de toucinho, porcos e gado. Produtos que juntos representavam mais de $60 \%$ do volume das exportações.

A crise da mineração aliada às perspectivas de mercado para os produtos mineiros pode ter alterado de forma significativa a produção agropastoril que, em muitas localidades foram deixando de ser exclusivamente para o abastecimento familiar, o que pode ter 
contribuído para o êxodo mineiro para outras regiões como o Oeste Paulista, o Triângulo Mineiro e o Sul de Goiás a partir dos fins do século XVIII. Movimento migratório que pode ter se intensificado ao longo da primeira metade do século XIX.

Silva e Sousa (apud TELES, 1978), em sua Memória Estatística da Província de Goiás, produzida, em princípios do século XIX, relata que no julgado de Santa Cruz, era muito grande a presença de mineiros que, em sua maioria, eram roceiros e criadores que adentravam com relativa frequência na região à procura de terras para estabelecer-se:

[...] se augmentão cada vez mais com os Geralistas, que então a procurar estabelecimentos, sendo que cada hum dos roceiros he também hum creador, que tem segundo as suas posses, gados, que apascentão em commum (SILVA e SOUZA apud TELES,1978, p. 160).

Quando chegava à determinada localidade os posseiros:

[...] dividiam as terras entre os familiares e agregados - que poderiam ser parentes ou não. $O$ preparo da terra para o cultivo e pastagem requeria um esforço conjunto de todos os componentes do núcleo familiar extenso, pois na época todo o trabalho era feito com o uso dos braços, tendo como instrumentos básicos de trabalho a enxada, o machado e a foice, sendo muito lento e com baixa rentabilidade produtiva. Gradativamente as famílias iam construindo benfeitorias: áreas cercadas de lascas de aroeira ou madeira branca, valos e batumes e córregos ou rios, construção da sede com currais e quintais com mangueiro, rego d'água, monjolo, paiol, engenhoca e moinho; o quintal, por sua vez, era formado com uma grande variedade de arvoredos frutíferos. As casas dos proprietários eram erguidas sob uma estrutura de madeira, assoalhadas, geralmente de pau-a-pique ou adobe, barreadas, caiadas e cobertas por telhas. Possuíam sempre uma planta retangular, com telhado de duas águas e uma repartição interna simples. Geralmente, eram sem forro sobre um porão e às vezes de terra batida. O mobiliário era sempre rudimentar. Não tinham nenhuma função agrícola. As habitações dos escravos, lavradores agregados e pequenos proprietários eram predominantemente de pau-a-pique e barro, coberta de palhas de palmeira, de capim, raramente de telhas. 0 mobiliário também era muito escasso, restringindo-se a bancos e mesas toscas e alguns utensílios básicos de cozinha, algumas peças de roupas e de cama. Dormiase sobre girais fixos de madeira roliça presa ao chão, forrados com colchão de palha ou capim. As casas de uma maneira geral eram construídas em locais que não exigiam movimento de terras e na proximidade de cursos d'água, erguidas sobre uma estrutura de madeira com ripas e troncos tirados do mato, cobertos de telhas ou com folhas de buriti ou bacuris. $O$ barreamento era feito geralmente com barro misturado com estrume de gado. Para iluminação utilizava-se do candeeiro de barro ou de metal umedecidos em algodão torcido com banha de porco ou azeite de mamona (OLIVEIRA, 2006, p. 46-47).

Conforme análise do perfil demográfico da população residente em Goiás, ela era predominantemente mestiça (parda) e negra e encontrava-se espalhada por todo o 
território goiano. Independente do grupo étnico, as características demográficas relatadas por Silva e Sousa leva a supor que a maioria dos migrantes que entravam em Goiás na primeira metade do século XIX era de famílias pobres e excluídas, cuja situação social pode ter se agravado com a crise da produção aurífera e, principalmente, das mudanças que estavam acontecendo na produção agropastoril mineira que, deixava de ser, exclusivamente voltada para o abastecimento local e familiar para uma economia mais de mercado. 0 objetivo passou a ser a produção para um mercado interno de maiores proporções situados no Rio de Janeiro e, posteriormente, São Paulo que se especializaram na produção de café para o mercado externo.

Nesta perspectiva, a referida análise parte das observações e apontamentos descritivos de Silva e Sousa, em sua obra Memória Estatística de Província de Goiás, que foi editada na Revista Histórica do IHGB, em segunda edição, em 1872. Além de uma descrição detalhada dos principais termos e julgados de Goiás de princípios do século XIX, Silva e Sousa também lançou mão "da primeira análise estatística que se permite fazer uma comparação mais detalhada da população livre e escrava que foi elaborada no governo de Francisco de Assis Mascarenhas em 1804" (FUNES, 1986, p. 107, grifo nosso).

A partir desta análise descritiva de Silva e Sousa, dos julgados existentes em Goiás em 1804, quando foi realizado o levantamento estatístico, procedeu-se a análise dos dados conforme a atividade econômica dominante: mineração(amarelo ouro), agropecuária (verde) e mineração/agropecuária (amarelo esverdeado), conforme disposto no Quadro 3. 


\begin{tabular}{|c|c|c|c|c|c|c|c|c|c|c|c|c|c|c|c|}
\hline & & & & & adro 3 & Populaç & Capitania & e Goiá & $(1804)^{*}$ & & & & & & \\
\hline \multirow[t]{3}{*}{ Termos } & \multicolumn{6}{|c|}{ Homens Livres } & \multirow[t]{3}{*}{ Escravos } & \multicolumn{6}{|c|}{ Mulheres Livres } & \multirow[t]{3}{*}{ Escravos } & \multirow[t]{3}{*}{ Total } \\
\hline & \multicolumn{2}{|c|}{ Brancos } & \multicolumn{2}{|c|}{ Negros } & \multicolumn{2}{|c|}{ Pardos } & & \multicolumn{2}{|c|}{ Brancas } & \multicolumn{2}{|c|}{ Negras } & \multicolumn{2}{|c|}{ Pardas } & & \\
\hline & Cas. & Sol. & Cas. & Sol. & Cas. & Sol. & & Cas. & Sol. & Cas. & Sol. & Cas. & Sol. & & \\
\hline \multicolumn{16}{|l|}{ SUL } \\
\hline Vila Boa & 106 & 504 & 25 & 388 & 118 & 1090 & 2637 & 84 & 525 & 28 & 571 & 137 & 1466 & 1785 & 9474 \\
\hline Meia Ponte & 124 & 462 & 57 & 248 & 184 & 734 & 1356 & 120 & 562 & 40 & 364 & 200 & 796 & 926 & 6173 \\
\hline Santa Luzia & 33 & 173 & 32 & 290 & 48 & 365 & 1037 & 33 & 126 & 40 & 470 & 149 & 395 & 538 & 3729 \\
\hline Santa Cruz & 122 & 304 & 17 & 71 & 79 & 324 & 617 & 113 & 339 & 21 & 110 & 83 & 322 & 380 & 2904 \\
\hline Desemboque & 200 & 410 & 02 & 30 & 85 & 161 & 413 & 209 & 384 & 02 & 28 & 84 & 118 & 247 & 2373 \\
\hline Pilar & 40 & 214 & 18 & 174 & 110 & 493 & 768 & 40 & 236 & 19 & 282 & 131 & 636 & 496 & 3657 \\
\hline Crixás & 08 & 40 & 15 & 153 & 25 & 174 & 422 & 08 & 23 & 19 & 256 & 26 & 222 & 212 & 1603 \\
\hline \multicolumn{16}{|l|}{ NORTE } \\
\hline Traíras & 49 & 149 & 114 & 428 & 268 & 787 & 1624 & 14 & 160 & 108 & 650 & 250 & 802 & 1183 & 6586 \\
\hline Cavalcante & 66 & 128 & 68 & 183 & 155 & 418 & 735 & 58 & 86 & 67 & 198 & 178 & 383 & 456 & 3179 \\
\hline São Félix & 10 & 29 & 25 & 142 & 60 & 243 & 331 & 10 & 29 & 26 & 169 & 60 & 310 & 310 & 1754 \\
\hline Arraias & 42 & 32 & 32 & 92 & 154 & 184 & 382 & 42 & 23 & 42 & 172 & 154 & 213 & 187 & 1751 \\
\hline Conceição & 46 & 51 & 44 & 235 & 94 & 274 & 304 & 46 & 56 & 43 & 245 & 95 & 181 & 380 & 2094 \\
\hline Natividade & 37 & 79 & 72 & 58 & 88 & 421 & 925 & 13 & 72 & 91 & 433 & 94 & 410 & 604 & 3397 \\
\hline Carmo & 18 & 32 & 25 & 170 & 50 & 182 & 625 & 19 & 12 & 30 & 204 & 62 & 225 & 219 & 1873 \\
\hline TOTAL & 901 & 2607 & 546 & 2662 & 1518 & 5850 & 12176 & 809 & 2633 & 576 & 4152 & 1705 & 6479 & 7933 & 50547 \\
\hline
\end{tabular}

Fonte: Dados Extraídos de Funes (1986, p. 108); Silva e Souza (1874, p. 429-510)

*Legenda:Verde Claro: Prevalecia Mineração e Agropecuária; Verde Escuro: Prevalecia Agropecuária; Amarelo Ouro: Prevalecia Mineração. 
Conforme observação descritiva de Silva e Sousa, os julgados de Vila Boa, Meia Ponte e Santa Luzia ao sul e, Traíras, Cavalcante e Arraias ao norte, embora já tivessem expressiva estrutura produtiva agropastoril, a mineração continuava sendo praticada expressivamente, embora, não era mais a principal atividade produtiva nestas localidades. Já, nos julgados de Pilar e Crixás ao sul e, Natividade e Carmo (Porto Imperial), ao contrário, a atividade mineradora aurífera persistia e dava seus últimos suspiros. No entanto, a atividade agropastoril começava a ganhar força e era perceptível o seu desenvolvimento conforme o seu relato. Já, nos julgados de Santa Cruz, Desemboque ao sul e, São Félix e Conceição (Barra do Palma) a atividade agropastoril era única e a mineração já havia ficado na lembrança dos antepassados.

A partir do levantamento estatístico realizado pelo então capitão general da Capitania de Goiás em 1804, observando as peculiaridades relatadas por Silva e Souza, pretende-se traçar o perfil demográfico da população goiana, em um contexto histórico, que marcado pela transição da mineração para a pecuária. Conforme os dados estatísticos, a população goiana em 1804 era de 50.547 pessoas, sendo que, deste total, 59\% (29.913) residiam nos julgados do sul e $41 \%$ (20.634) se concentravam na região norte.

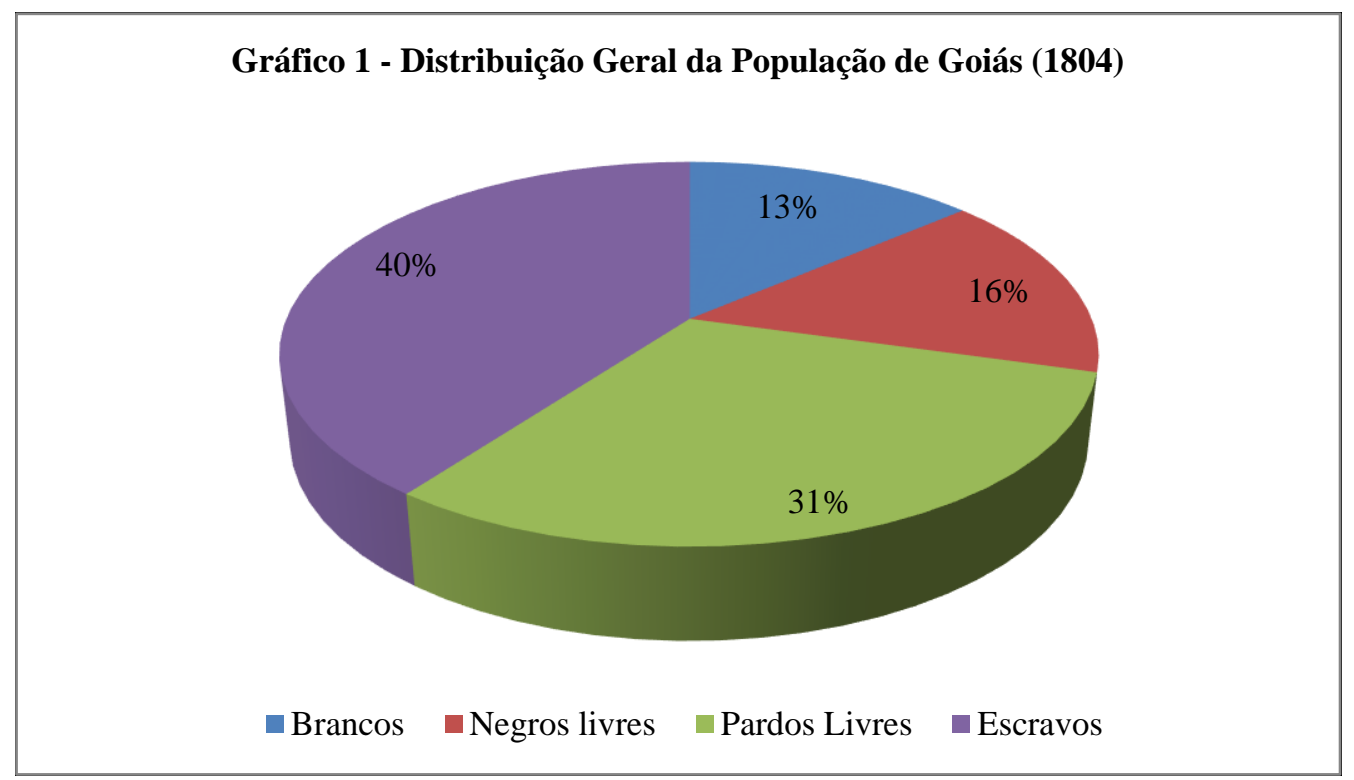

Fonte: Dados Extraídos de Funes (1986, p. 108); Silva e Souza (1874, p. 429-510)

De acordo com os dados estatísticos apresentados por Francisco Assis Mascarenhas, a população de Goiás em princípios do século XIX, era predominantemente negra e mestiça. Negros e pardos livres representavam $47 \%$ da população e os escravos $40 \%$, a população 
branca, por sua vez, era de apenas $13 \%$ do conjunto total da população. No entanto, apesar de ser grupo minoritário, eram os brancos que detinham a posse da terra e da riqueza. Quanto à condição social, cerca de $60 \%$ da população total da província era de livres, enquanto que os escravos representavam $40 \%$ da população.

Pode-se observar no Gráfico 2, tanto na Região Norte e na Região Sul de Goiás, a população livre e escrava, encontrava-se distribuída de forma equivalente.

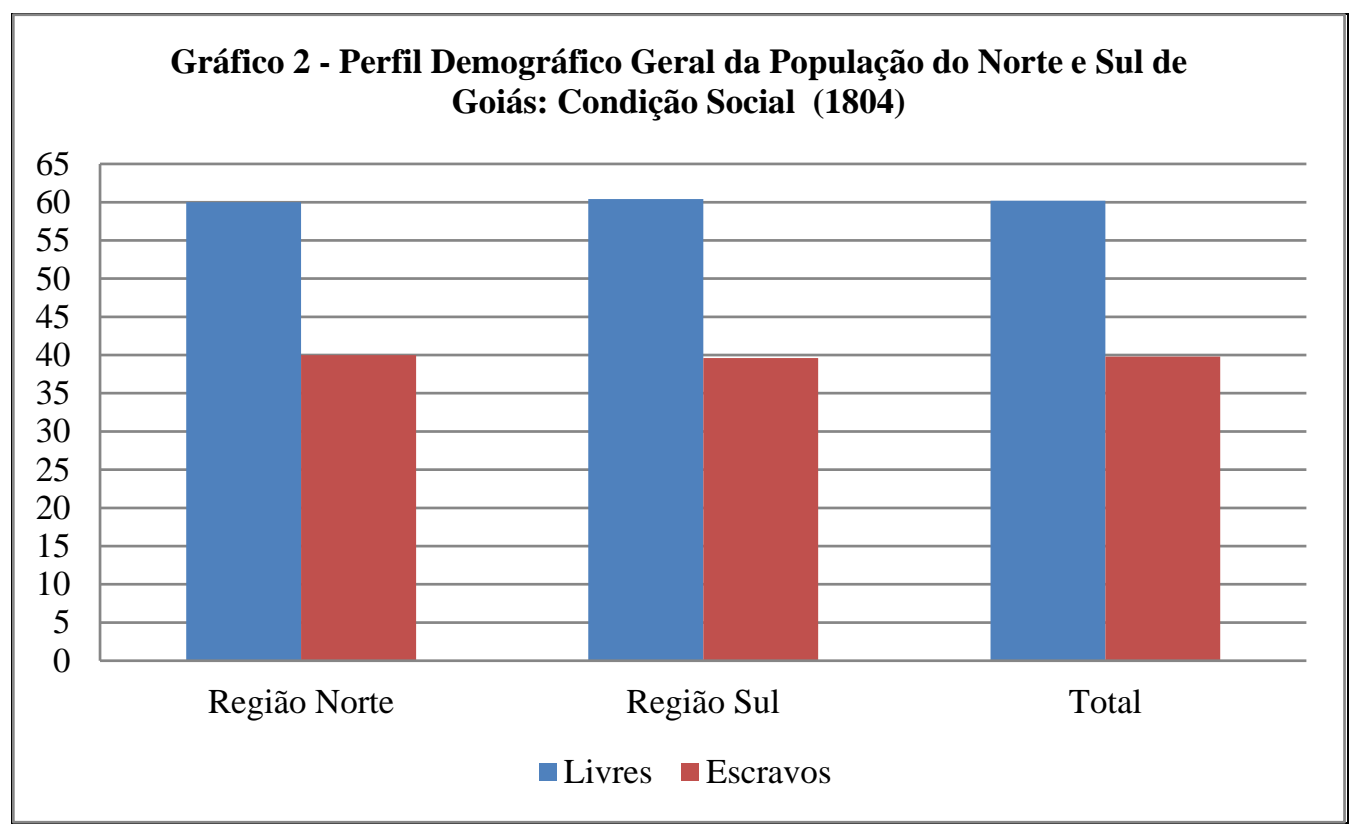

Fonte: Dados Extraídos de Funes (1986, p. 108); Silva e Souza (1874, p. 429-510)

No entanto, a maioria da população concentrava-se nos julgados mais antigos originários da atividade mineradora e agropastoril que, outrora fora os principais grandes centros de riqueza aurífera e ostentação, como os julgados de Vila Boa (atual cidade de Goiás) e Meia Ponte (atual Pirenópolis) que juntos, em 1804, detinham mais de $30 \%$ da população geral da capitania de Goiás.

Os dados apresentados por Silva e Sousa no Gráfico 3 mostram que $61 \%$ da população goiana residiam nos julgados mais dinâmicos, ainda sob a sombra do esplendor aurífero, mas, com a adaptação às novas atividades ligadas à agricultura e, especialmente, na pecuária. Porém, Silva e Sousa (1978) relata que nestas localidades havia muitas terras devolutas e a prática do plantio não eram modernos e eficientes. Da mesma forma, a criação de gado seguia a tradição de costume, era criado solto nos pastos e aos cuidados da natureza. 
Gráfico 3 - Distribuição Geral da População de Goiás: Atividade Econômica Predominante (1804)

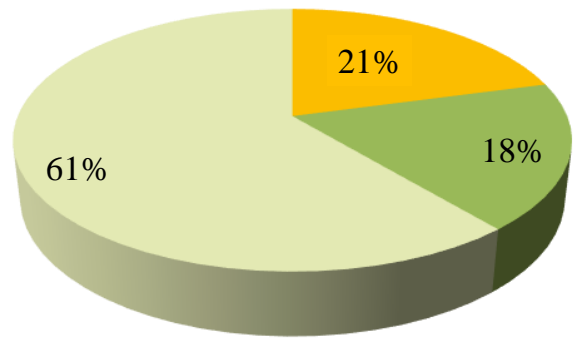

$\square$ Região Mineradora $\square$ Região Agropastoril $\llbracket$ Região de Mineração/agropastoril

A exploração das jazidas de ouro, outrora muito fecundas, encontrava-se praticamente abandonadas, por falta de mão de obra e, principalmente, de recursos técnicos modernos que possibilitasse a extração mais profunda do valioso metal. Os meios de transportes de mercadorias, ainda eram muito incipientes, no sul de Goiás, "os moradores ainda faziam os transportes dos seus gêneros em animaes Cavallares, usando ainda pouco dos carros de bois com que se serve em outros lugares" (SILVA e SOUSA apud TELES, 1978, p.157, grifo nosso).

Nas regiões tipicamente agropastoris residia apenas $18 \%$ da população. Nestas localidades havia, também, muitas terras devolutas. Dentre os julgados mais expressivos, no sul de Goiás, segundo Silva e Sousa, eram os de Santa Cruz e Desemboque. Em Santa Cruz, havia:

[...] 816 roças mais ou menos consideráveis, e algumas insignificantes: incluindo neste número 19 engenhos, que fabricão asaducar, agoadente e rapaduras, que nem todos trabalhão em todos os anos [...] Os lavradores plantam milho, feijão, arroz, mandioca e algumas raízes de comestíveis, pouco algodão, café, e tabaco, so para o seu uso. Trabalhão pelo methodo de toda a Província, roção, plantão, e colhem sem que as terras tenhão outro benefício senão os saes das cinzas, que ficão das queimadas (SILVA e SOUSA apud TELES, 1978, p.159).

Segundo Silva e Sousa, a produção agrícola era predominantemente familiar e voltada, quase que exclusivamente, para o consumo familiar e os métodos de cultivo eram bem rudimentares baseados na roçagem utilizando-se, basicamente, do machado, enxada e fogo. Dentre os produtos naturais da terra, destaque para a pecuária que já começava a ganhar certo incremento com a chegada de mineiros geralistas "que entrão a procurar 
estabelecimentos, sendo que cada hum dos roceiros ha também hum creador, que tem segundo as suas posses, gados, que apascentão em commum" (SILVA e SOUSA apud TELES, 1978, p.160).

Nas regiões mineradoras concentravam-se $21 \%$ da população, com destaque para os julgados de Pilar no Sul e Natividade ao Norte, que juntos, concentravam $13,9 \%$ da população de Goiás. Embora a mineração ainda fosse a principal atividade, Silva e Sousa afirma que em Natividade existiam:

[...] minas de ouro de subido quilate, e não se aproveitão, nem os mesmos ribeiros no seio veia, pela falta de captivos, e pela negligência da Policia, que não faz trabalhar os libertos, e por isso estão todas em abandono; falta além disto a arte que facilita, e regula os trabalhos por hum modo vantajoso (SILVA e SOUSA apud TELES, 1978,p.179).

Apesar da riqueza aurífera ainda existente no solo, os escassos recursos financeiros, a falta de mão de obra e recursos técnicos mais eficazes para a extração do ouro eram os principais empecilhos para o seu desenvolvimento. Além da mineração, nestas localidades produziam, também, gêneros alimentícios nos moldes tradicionais já apontados, os únicos artigos comercializáveis, além do gado, eram alguns produtos agromanufaturados como doces, aguardente e demais derivados da cana-de-açúcar que eram comercializados nos pequenos lugarejos e vilas próximas.

Os dados demográficos apontados por Francisco de Assis Mascarenhas mostram uma relativa semelhança no perfil demográfico das populações que habitavam as regiões de atividade mineradora e agropastoril. Na região mineradora os brancos não chegavam a corresponder a $10 \%$ da população; já em regiões com características agropastoris, estes representavam mais de 25\%; nas localidades de atividades mineradora e agropastoril, a população branca total girava em torno de $12 \%$. Bem como, nas regiões mineradora e mineradora/agropastoril conforme nota-se no Gráfico 4, concentravam mais de $40 \%$ dos escravos. A taxa de masculinidade da população escrava nestas localidades era bem maior, conforme se pode notar: $26 \%$ na região mineradora de escravos contra apenas $14,5 \%$ de escravas; na região mineradora/agropastoril $25,2 \%$ de escravos contra $16,5 \%$ de escravas. 


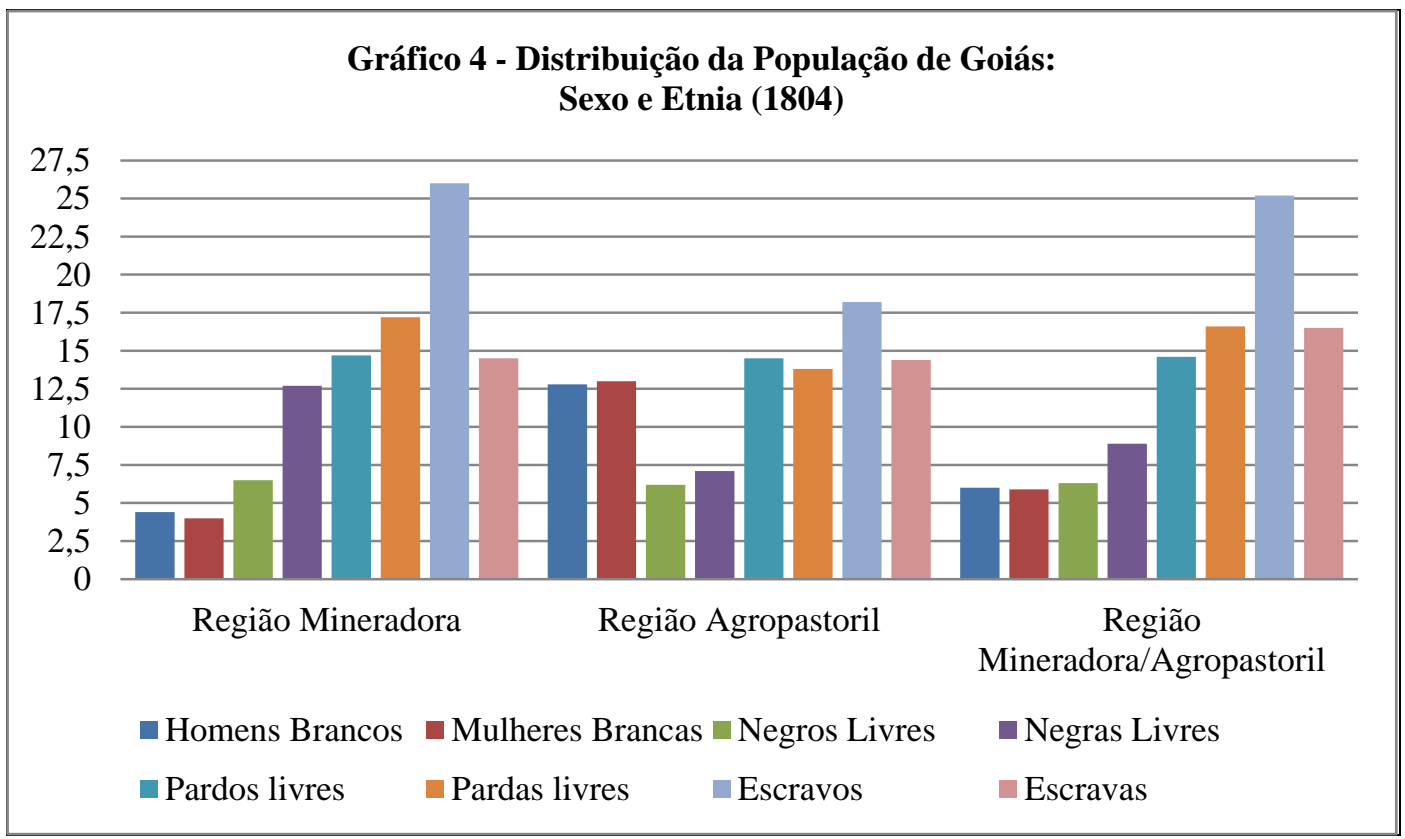

Fonte: Dados Extraídos de Funes (1986, p. 108); Silva e Souza (1874, p. 429-510)

Já na região agropastoril, de uma maneira geral, havia certo equilíbrio entre os sexos, exceto, entre a população escrava. Na população livre, entre os brancos a proporção era de $12,8 \%$ de homens e $13 \%$ de mulheres; negros livres eram de $6,2 \%$ contra $7,1 \%$ de negras livres; já os pardos livres representavam 14,5\% contra $13,8 \%$ de pardas livres; enquanto que entre os negros, a desproporção era um pouco maior: os escravos representavam $18,2 \%$ e as escravas $14,4 \%$. Porém, entre os brancos havia praticamente um equilíbrio entre homens e mulheres nas regiões de mineração, agropecuária e mineradora/agropastoril.

Pode-se concluir que nas localidades em que a atividade mineradora era predominante havia um desequilíbrio maior entre os sexos na população cativa, onde a taxa de masculinidade, nestas localidades, mantinha-se na proporção média de $25 \%$ de homens contra 15\% de mulheres. Enquanto que, nos demais segmentos étnicos livres ocorriam o contrário, a proporção de mulheres era relativamente muito maior do que de homens.

Os dados do levantamento estatístico de 1804 apontam que a proporção de brancos era maior nas localidades em que a agricultura e a pecuária já eram atividades econômicas dominantes. Nestas, os brancos representavam $25,8 \%$ da população total, os escravos $39,6 \%$, pardos livres $29,2 \%$ e negros livres $12,6 \%$. 


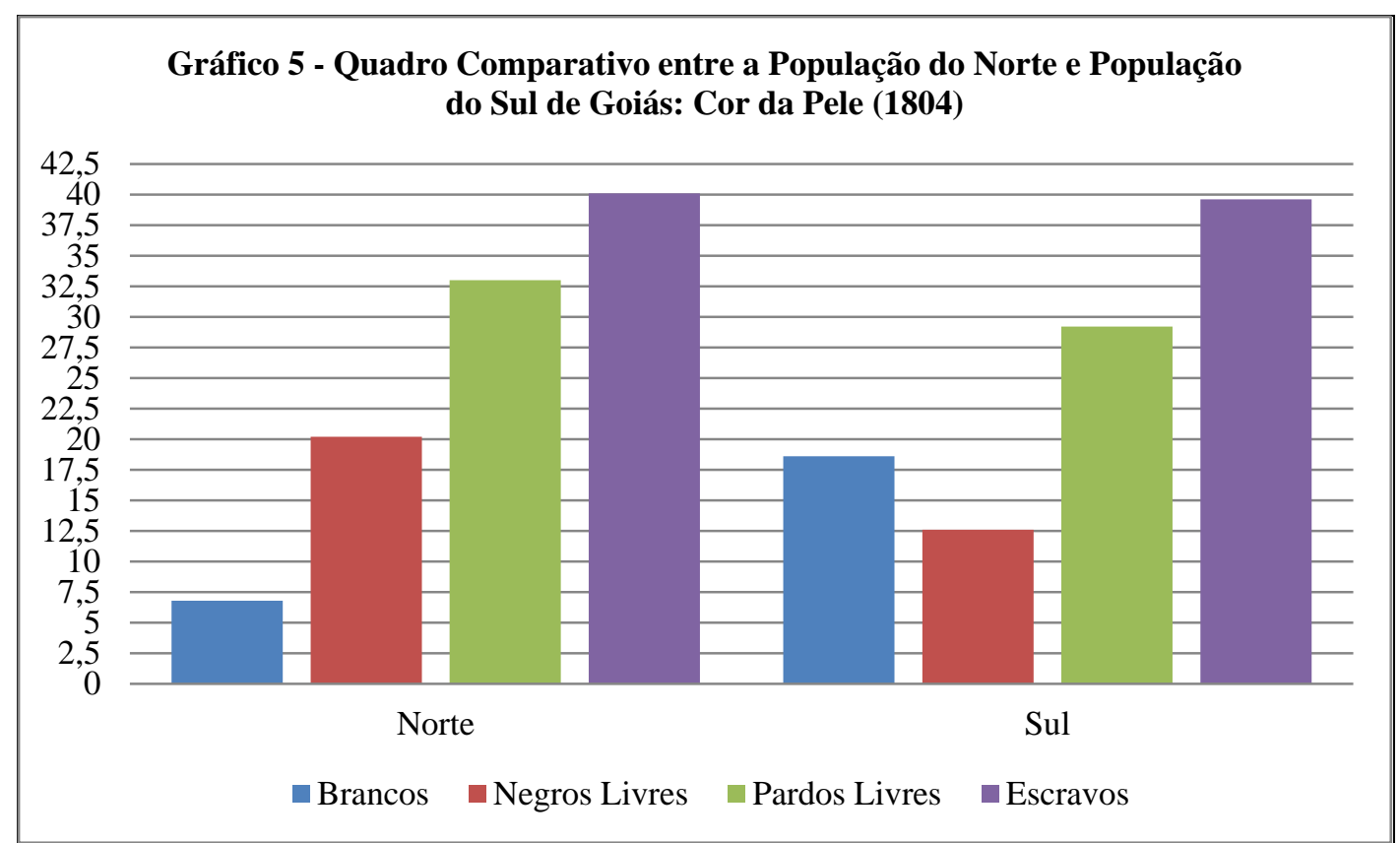

Fonte: Dados Extraídos de Funes (1986, p. 108); Silva e Souza (1874, p. 429-510)

No conjunto geral da população no norte de Goiás era composta por $6,8 \%$ de brancos, $20,2 \%$ de negros livres, $33 \%$ de pardos livres e $40,1 \%$ de escravos. Já no sul os brancos representavam $18,6 \%$ da população, negros livres $12,6 \%$, pardos livres $29,2 \%$ e os escravos 39,6\%. A população de Goiás em princípios do século XIX era composta, majoritariamente, por negros e pardos que juntos correspondiam a $80 \%$ da população goiana. O que pressupõe que a maioria dos migrantes oriundos de Minas Gerais (ao sul) e do Nordeste (especialmente, da Bahia) ao Norte, que se deslocavam para Goiás eram compostos por indivíduos pobres, em sua maioria, negros e pardos livres que deixavam suas terras de origem onde, provavelmente eram escravos, e se dirigiam para o sertão em busca de terras devolutas para se estabelecer com seus familiares, utilizando como recurso, a aquisição de uma gleba de terra através da posse momentânea em comunidades quilombolas e, principalmente, se instalavam nas propriedades como camaradas ou agregados.

A predominância da população negra e mestiça em relação à branca, também, foi notada por Oliveira (2006) na análise de um montante de 161 registros de casamentos realizadas na capela de Nossa Senhora do Carmo dos Morrinhos entre os anos de 1835 a 
1849: os pardos livres representavam $51 \%$ dos noivos e noivas, brancos $33 \%$ e negros $16 \%{ }^{3}$. O povoado de Nossa Senhora do Carmo dos Morrinhos (atual Morrinhos/GO) era uma região de vocação agropastoril, os dados apresentados acabam sendo condizentes com o levantamento estatístico de 1804. Pode-se estimar a partir destes dados que a população do povoado era constituída, em sua maioria, na primeira metade do século XIX, em cerca de $70 \%$ de pardos e negros. Os registros de casamento também apontam para uma prática, que era muito vigente no Brasil desde os tempos coloniais, em que o matrimônio se caracterizava como sendo:

[...] um verdadeiro aparthaid racial: brancos casavam-se com brancos, pardos com pardos e negros com negros. Muito raramente ocorriam matrimônios entre noivos de grupos étnicos diferentes. Em um total de 161 registros de casamentos, encontraram-se apenas dois casais com diferenciação étnica: Luciano José de Magalhães, crioulo forro, que se casou com Maria Antônia Hipólita, parda livre, em 15 de outubro de 1839 e Serafim Soares de Sousa, pardo livre, que se casou com Joana Simplícia de Jesus, branca, em 28 de janeiro de 1842. Estas evidências podem levar a outras hipóteses e discussões sobre o processo de miscigenação, que é uma característica marcante na população do sul de Goiás, na primeira metade do século XIX: sua ocorrência efetuava-se, provavelmente, fora do matrimônio (OLIVEIRA, 2006, p.58-59).

Os casamentos ocorriam, praticamente, entre indivíduos de uma mesma etnia, embora, o casar-se legalmente não era uma prática muito comum para a maioria das pessoas ou por falta de recursos financeiros para custear as despesas de um casamento e, também, pelas dificuldades de acesso a um padre e uma paróquia. Mesmo que tivessem recursos, embora não tivesse moeda corrente em mãos ${ }^{4}$, as tradições e os costumes da época levavam a maioria da população a optar por uma vida conjugal informal, o amasiamento.

Os dados do levantamento estatístico de 1804 , conforme disposto no Quadro 3, pressupõe que a prática do amasiamento era muito comum, pois, apenas $12 \%$ da população livre era casada, enquanto que, $88 \%$ permanecia solteira, em uma época "que cerca de $80 \%$

\footnotetext{
${ }^{3}$ Nos registros de casamentos o pároco utilizava a cor preta quando se referia a negros escravos ou livres. Portanto na análise, os noivos que foram denominados como sendo "preto(a)" ou "crioulo(a)" foram considerados pelo pesquisador como sendo negros.

${ }^{4}$ OLIVEIRA, Hamilton Afonso de. A construção da riqueza no sul de Goiás (1835-1910). Tese de doutorado. Franca/SP: UNESP, 2006. Disponível em:

$<$ http://www.dominiopublico.gov.br/pesquisa/DetalheObraForm.do?select_action=\&co_obra=98827>. Acesso em: 13 dez. 2014.
} 
dos casamentos na região sul de Goiás entre os anos de 1836 a 1849 era contraída entre os 13 e 25 anos [...] as mulheres contraiam o matrimônio com a idade entre 13 e 20 anos e os homens, com idade entre 17 e 25 anos"(OLIVEIRA, 2006, p. 60). No entanto, a prática da escolha de um esposo ou esposa de um mesmo padrão étnico ocorria tão somente no ato de consumação legal de um matrimônio.

Porém, nas relações extraconjugais e nas práticas do concubinato tão padrão não era seguido, conforme, se observa nos relatos de viajantes como Saint-Hilaire (1975) Phol (1949), Aires Casal (1874) etc. que percorreram Goiás na primeira metade do século XIX. No entanto, a proporção de pessoas casadas era um pouco maior entre a população livre das localidades agropastoris, onde além da atividade ter por característica maior fixação do homem a terra, a produção tinha um caráter familiar, o que pressupõe um maior equilíbrio entre a população feminina e masculina, ao contrário, das regiões onde prevaleciam as atividades mineradoras, conforme é possível observar no Gráfico 6:

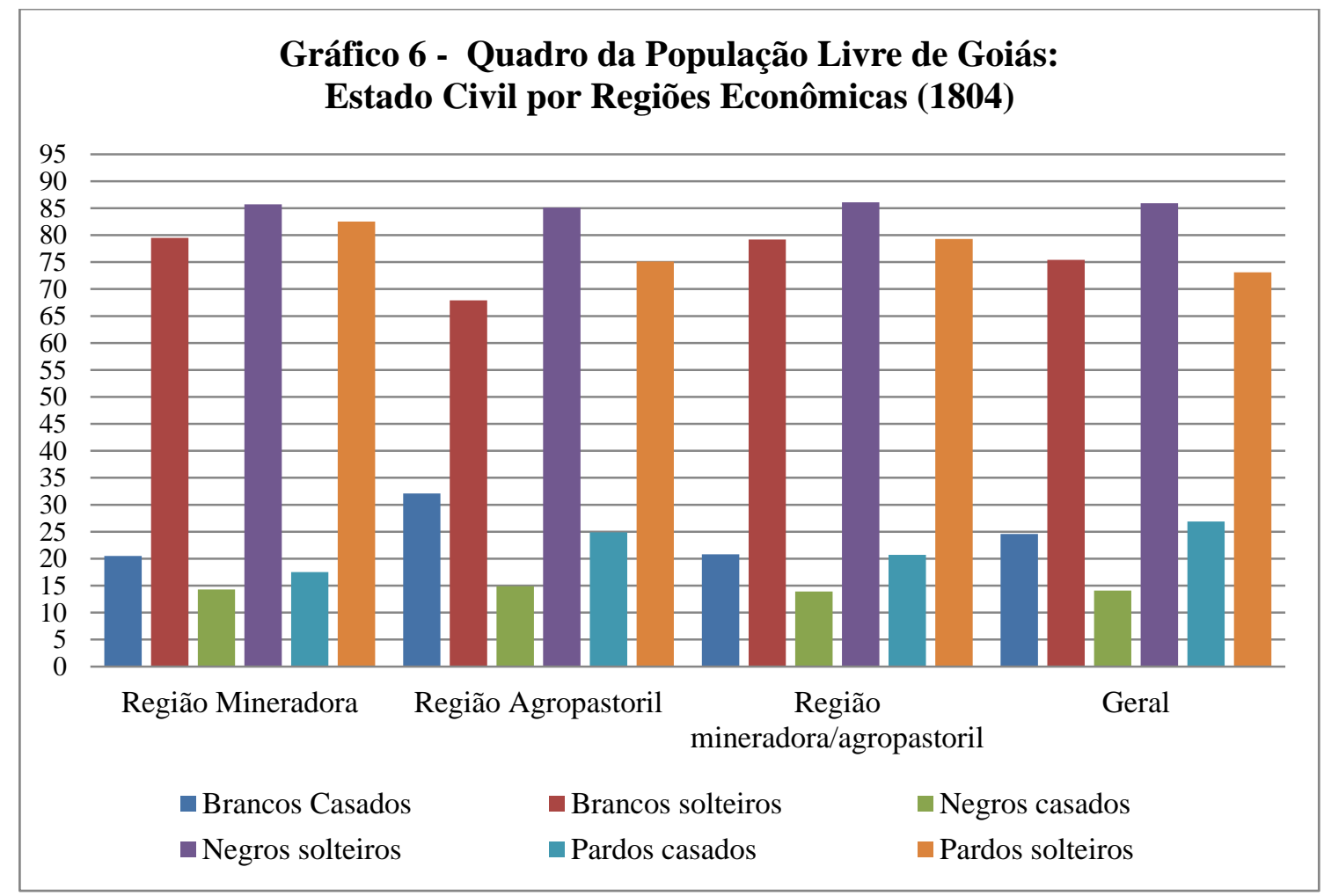

Fonte: Dados Extraídos de Funes (1986, p. 108); Silva e Souza (1874, p. 429-510)

De uma maneira geral, a proporção de pessoas casadas entre os brancos e pardos livres era quase equivalente, em detrimento dos negros livres, cuja proporção de contraentes ao matrimônio era bem menor, apenas $11,1 \%$, enquanto que, entre os brancos 
o índice era de $24,6 \%$ e, entre os pardos livres, $26,9 \%$. Se levar em consideração os aspectos da atividade econômica principal, nos julgados em que a atividade agropastoril era predominante a proporção de casados era maior do que nas regiões mineradoras. Conforme se apresenta no Gráfico 6, 32,1\% dos brancos eram casados, enquanto que, nas localidades em que prevalecia a atividade mineradora era de apenas cerca de $20 \%$; já, os negros livres, a proporção de casados era equivalente entre as regiões, com aproximadamente 14\%; os pardos livres casados era de $24,9 \%$ nas regiões de atividade agropastoril, na mineradora, apenas $17,5 \%$ haviam contraído o matrimônio.

Neste mundo tipicamente agrário cujas atividades praticamente centravam-se no abastecimento familiar não havia "a possibilidade de um homem viver e progredir sem ter mulher e filhos. Pois, estes ajudam os pais no trabalho da casa e da lavoura de cereais" (RAMALHO, 1986, p. 45). Ao analisar 536 inventários que compreendem os anos de 1843 a 1910, apenas $25 \%$ dos inventariados do período, tinham pelo menos dois filhos:

[...] os inventariados com riqueza avaliada em até $1.000 \$ 000$ (um conto de réis), $39,7 \%$ possuíam um número igual ao superior a seis filhos; na categoria dos que possuíam riqueza de $1.000 \$ 001$ a $4.000 \$ 000$ contos de réis, 47,5\%; na categoria entre $4.000 \$ 001$ a $7.000 \$ 000$ contos de réis, $50,6 \%$; entre os que detinham acima de $7.000 \$ 000$ (sete contos de réis), $56,7 \%$, sendo que, destes, $16,9 \%$ eram pais de dez ou mais filhos (OLIVEIRA, 2006, p. 61).

Pode se concluir que, no século XIX em Goiás, os principais símbolos de poder e o status social centravam-se: na posse da terra e na cor da pele que, conjugado com uma prole extensa e um grande número de dependentes é que assentavam o poder e o prestígio de um indivíduo e de sua família perante uma sociedade da época, em que, aproximadamente 95\% da população eram analfabetas e as mulheres eram educadas e preparadas, em sua grande maioria, para serem boas esposas e mães.

\section{Considerações Finais}

O presente ensaio teve a pretensão, em primeiro lugar, de refletir sobre o processo de ocupação do sul de Goiás que teve sua história intimamente relacionada com as transformações sociais e econômicas que começaram a ocorrer no Sudeste, especialmente, em Minas Gerais em princípios do século XIX, a partir da chegada da Família Real Portuguesa 
ao Brasil em 1808, que resultou na Abertura dos Portos e na elevação da Colônia à condição de Reino Unido a Portugal e Algarves.

As medidas contribuíram para que Minas Gerais passasse por uma reestruturação em suas atividades econômicas e foi deixando de produzir apenas gêneros de primeira necessidade para o abastecimento familiar para uma produção em larga escala, tendo em vista o abastecimento interno do Rio de Janeiro e, posteriormente, São Paulo. Estas transformações podem ter sido determinantes para motivar os deslocamentos migratórios para o centro, sudeste, sudoeste e, principalmente, para o sul de Goiás provocando a ocupação definitiva de do seu território.

Outro aspecto observado a partir dos dados do levantamento estatístico publicado em 1804, pelo então capitão Geral da Capitania de Goiás Francisco de Assis Mascarenhas e da obra Memória sobre o descobrimento, população e cousas mais notáveis da Capitania de Goyaz do Cônego Luís Antônio da Silva e Souza, foi possível traçar o perfil da população e alguns aspectos das atividades econômicas de Goiás de princípios do século XIX, numa fase que pode ser caracterizada como de transição da mineração para a pecuária.

A partir das informações descritas por Silva e Souza e do levantamento estatístico foi possível perceber algumas características da população residente nas principais vilas e julgados existentes em Goiás, onde a atividade econômica dominante podia determinar certos aspectos peculiares da demografia que caracterizam uma sociedade já em transformação nos momentos de transição da atividade mineradora para a pecuária.

\section{REFERÊNCIAS}

BERGAD, Laird W. Escravidão e história econômica: demografia de Minas Gerais (1720-1888). Bauru/SP: EDUSC, 2004.

BRIOSCHI, Lucila R. Entrantes no sertão do Rio Pardo: o povoamento da freguesia de Batatais séculos XVIII e XIX. São Paulo: CERUS, 1991.

CASAL, Manuel Aires de. Corografia Brasílica. Belo Horizonte/São Paulo: Itatiaia/EDUSP, 1976.

CASTELNAU, Francis. Expedição às regiões centrais da América do Sul. São Paulo: Nacional, 1941.

FUNES, Eurípedes Antônio. Goiás (1800-1850): um período de transição da mineração à agropecuária. Goiânia: UFG, 1986.

LOURENÇO, Luís Augusto Bustamante. O Triângulo Mineiro, do Império à República. Uberlândia: EDUFU, 2010. 
LUZ, Maria Amélia de Alencar. Estrutura fundiária em Goiás: consolidação e mudanças (1850-1910). 1982. Dissertação (Mestrado em História) - Instituto de Ciências Humanas da Universidade Federal de Goiás. Goiânia, 1982.

OLIVEIRA, Hamilton Afonso de. A construção da riqueza no sul de Goiás (1835-1910). Tese (Doutorado em História) - Universidade Estadual Paulista Júlio de Mesquita Filho, Franca, 2006. Disponível em:

<http://www.dominiopublico.gov.br/pesquisa/DetalheObraForm.do?select_action=\&co_obra=98827 >. Acesso em: 13 dez. 2014.

A marcha das migrações: a ocupação e a colonização do Sul de Goiás (1800-1850). Revista História, Goiânia, v. 1, n. 1, jan./jun., 2008. Disponível em:

<http://www.revistas.ufg.br/index.php/historia/article/viewFile/5421/4438>. Acesso em: 15/01/2015.

PHOL. J. Emmanuel. Viagem ao interior do Brasil. São Paulo: EDUSP, 1975.

RAMALHO, José Ricardo. A posse e o uso da terra e relações de trabalho em Mossâmides. In: BRANDÃO, Carlos Rodrigues; RAMALHO, José Ricardo. O campesinato goiano: três estudos. Goiânia: UFG, 1986.

SAINT-HILAIRE, August de. Viagem às nascentes do Rio São Francisco. São Paulo: EDUSP, 1975.

SILVA e SOUSA, Luiz Antônio da. Memória sobre o descobrimento, população e cousas mais notáveis da Capitania de Goyaz. Revista Trimestral do Instituto Histórico e Geográfico Brasileiro. Rio de Janeiro: João Ignácio da Silva, 1874.

TELES, Gilberto de Mendonça. Vida e obra de Silva e Souza. Goiânia: Oriente, 1978. 